
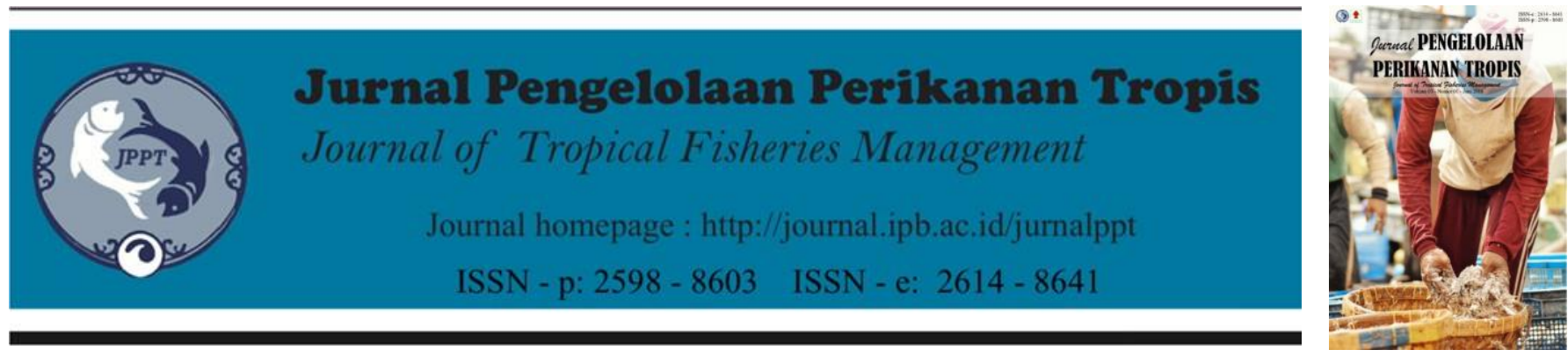

\title{
Preferensi Makanan Ikan Kembung Lelaki (Rastrelliger kanagurta Cuvier, 1816) Terhadap Klorofil-A
}

\author{
(Food Preference of Indian Mackerel (Rastrelliger kanagurta Cuvier, 1816) Against Chlorophyll-A)
}

\author{
Sahda Salsabila*, Ridwan Affandi \\ Departemen Manajemen Sumberdaya Perairan, Fakultas Perikanan Dan Ilmu Kelautan, Institut Pertanian Bogor \\ Jl. Agatis, Kampus IPB Dramaga, Bogor, Jawa Barat, Indonesia
}

\begin{tabular}{l}
\hline ARTIKEL INFO \\
\hline Article History \\
Recevied: 18 Februari 2019 \\
Accepted: 5 Mei 2019 \\
\hline Kata Kunci: \\
Fitoplankton, ikan kembung lelaki \\
(Rastrelliger kanagurta), klorofil-a \\
Key words: Phytoplankton, indian \\
mackerel (Rastrelliger kanagurta), \\
chlorophyll-a
\end{tabular}

\section{Korespondensi Author}

Sahda Salsabila, Departemen

Manajemen Sumberdaya Perairan,

Fakultas Perikanan Dan Ilmu

Kelautan, Institut Pertanian Bogor

E-mail :

sahda_salsabila@apps.ipb.ac.id

\begin{abstract}
ABSTRAK
Kandungan klorofil-a yang tinggi akan berpengaruh pada meningkatnya jumlah fitoplankton dan diikuti oleh keberadaan zooplankton. Jumlah fitoplankton dan zooplankton berpengaruh pada organisme perairan lainnya, seperti ikan pelagis kecil. Ikan kembung lelaki merupakan ikan ekonomis dan banyak dikonsumsi masyarakat. Penelitian ini bertujuan untuk mengetahui hubungan komposisi makanan ikan kembung lelaki dengan konsentrasi klorofil-a. Penelitian ini dilaksanakan sejak Mei 2018 sampai September 2018, di Pelabuhan Perikanan Pantai (PPP) Lempasing, Lampung dengan pengambilan sampel sebanyak 240 ekor yang terdiri atas 140 ekor jantan dan 101 ekor betina. Hasil pengamata menunjukkan bahwa ikan kembung lelaki memanfaatkan fitoplankton, zooplankton, ikan, udang, dan crustace sebagai makanannya. Komposisi makanan fitoplankton kelas Bacillariophyceae mendominasi isi lambung ikan kembung lelaki selama waktu pengamatan. Konsentrasi klorofil-a di perairan Selat Sunda cenderung meningkat selama waktu pengamatan. Puncak komposisi fitoplankton terdapat pada bulan Agustus yang diduga terjadi upwelling. Komposisi fitoplankton terendah terdapat pada bulan Mei dengan konsentrasi klorofil-a di perairan lebih rendah daripada waktu lainnya.
\end{abstract}

\begin{abstract}
High chlorophyll-a content will affect the increasing number of phytoplankton and will be followed by the presence of zooplankton. The amount of phytoplankton and zooplankton can affect other aquatic organisms, such as small pelagic fish. Indian mackerel is an economical fish which consumed by many people. This reseacrh aims to determine the relation between indian mackerel's food composition and chlorophyll-a concentration. The research was conducted from May 2018 to September 2018, at the Coastal Fisheries Port (PPP) of Lempasing, Lampung, used some example fishes around 240, 140 male and 101 female fishes. The results of the observation show that indian mackerel consume phytoplankton, zooplankton, fish, shrimp, and crustace as food. The Bacillarophyceae dominates the stomach content during the observations time. Chlorophyll-a concentrations in the Sunda Strait tend to increase during the observation time. The peak composition of phytoplankton is on August, which is suspected to be upwelling. The lowest phytoplankton composition is on May with lower chlorophyll-a concentrations in water than the other observations time.
\end{abstract}

\section{PENDAHULUAN}

Klorofil-a dapat digunakan sebagai indikator kesuburan suatu perairan dengan mengetahui keberadaan fitoplankton dalam air. Kandungan klorofil-a dapat digunakan sebagai ukuran jumlah fitoplankton. Klorofil-a merupakan jenis pigmen terbesar yang terkandung dalam fitoplankton dan digunakan dalam proses fotosintesis. Fitoplankton merupakan organisme laut yang hanyut dan melayang dalam air serta mampu berfotosintesis. Sebaran klorofil-a di laut beragam baik secara geografis maupun kedalaman perairan. Sebaran konsentrasi klorofil-a tinggi pada perairan pantai dan pesisir karena masukan nutrien melalui runoff sungai dari daratan.

Makanan merupakan suatu zat, bahan, ataupun organisme yang dimanfaatkan oleh ikan untuk menunjang kelangsungan hidupnya. Ikan 
memanfaatkan energi yang berasal dari makanan untuk tumbuh, reproduksi, dan melangsungkan proses-proses fungsional organ tubuhnya. Jumlah dan jenis makanan mempengaruhi jenis dan jumlah populasi ikan di perairan tersebut. Kebiasaan makanan ikan merupakan jenis, kuantitas, dan kualitas makanan yang dikonsumsi oleh ikan dan pembelajaran mengenai hubungan ekologis ikan dengan organisme lain di perairan seperti, pemangsaan, persaingan, dan rantai makanan. Kebiasaan makan ikan secara alami dipengaruhi oleh beberapa faktor, seperti habitat, ukuran dan umur ikan, musim, periode harian mencari makanan, dan kesukaan terhadap jenis makanan tertentu. Ketersediaan makanan dapat menentukan jumlah populasi, pertumbuhan, reproduksi, dan dinamika populasi serta kondisi ikan di suatu perairan. Makanan ikan dalam satu spesies dapat berbeda dari waktu ke waktu karena adanya perubahan lingkungan. Fitoplankton berperan sebagai produsen primer yaitu organisme yang merubah senyawa anorganik menjadi senyawa organik dengan bantuan sinar matahari (Sihombing et al. 2015). Klorofil-a merupakan pigmen yang dimiliki oleh fitoplankton yang digunakan dalam proses fotosintesis. Klorofil-a merupakan indikator kesuburan perairan. Kandungan klorofil-a yang tinggi akan berpengaruh pada meningkatnya jumlah fitoplankton dan diikuti oleh keberadaan zooplankton. Jumlah fitoplankton dan zooplankton berpengaruh pada organisme perairan lainnya, seperti ikan pelagis kecil (Kasim et al. 2014).

Ikan membutuhkan energi yang diperoleh dari makanan untuk melakukan proses biologis yakni tumbuh, reproduksi, dan aktivitas metabolisme. Makanan ikan merupakan integrasi dari komponen ekologi penting yang mencakup perilaku, kondisi, pemanfaatan habitat, asupan energi, dan interaksi antar atau intraspesifik (Nath et al. 2015). Ikan kembung lelaki (Rastrelliger kanagurta) merupakan ikan pelagis kecil yang bersifat planktivora atau omnivora dengan komposisi makanan yang bervariasi (diatom, dinoflagellata, copepoda, krustasea, dan ikan) (Bhendarkar et al. 2014). Ikan kembung lelaki merupakan salah satu ikan ekonomis penting di perairan Selat Sunda yang didaratkan di Pelabuhan Perikanan Pantai (PPP) Lempasing, Kota Bandar Lampung, Provinsi Lampung. Ikan kembung lelaki merupakan ikan yang banyak diminati karena gizinya yang cukup tinggi dan harganya ekonomis. Selain itu, ikan pelagis kecil ini mudah sekali tertangkap karena bergerombol di permukaan laut pada musim-musim tertentu (Utami et al. 2014).

Ikan kembung lelaki merupakan ikan ekonomis dan banyak dikonsumsi masyarakat sehingga ketersediaan ikan tersebut harus tetap diperhatikan dalam jangka panjang. Informasi mengenai aspek makanan ikan kembung lelaki yang dikaitkan dengan suhu permukaan laut dan klorofil-a dibutuhkan sebagai dasar dalam pengelolaan sumberdaya Ikan kembung lelaki secara berkelanjutan.

\section{METODE}

\section{Lokasi Penelitian}

Penelitian ini dilakukan di sepanjang perairan Selat Sunda dengan lokasi pengambilan contoh di PPP Lempasing, Lampung. Ikan yang didaratkan di PPP Lempasing pada umumnya berasal dari perairan sekitar Pulau Tabuan, Pulau Legundi, Pulau Sebesi, Pulau Sebuku, Pulau Rakata, dan Pulau Sangiang. Pengambilan data primer dan data sekunder dilaksanakan secara berkala setiap bulan mulai dari bulan Mei 2018 sampai bulan September 2018. Analisis ikan contoh dilakukan di Laboratorium Biologi Perikanan, Departemen MSP, FPIK, IPB. Peta lokasi penelitian disajikan pada Gambar 1.

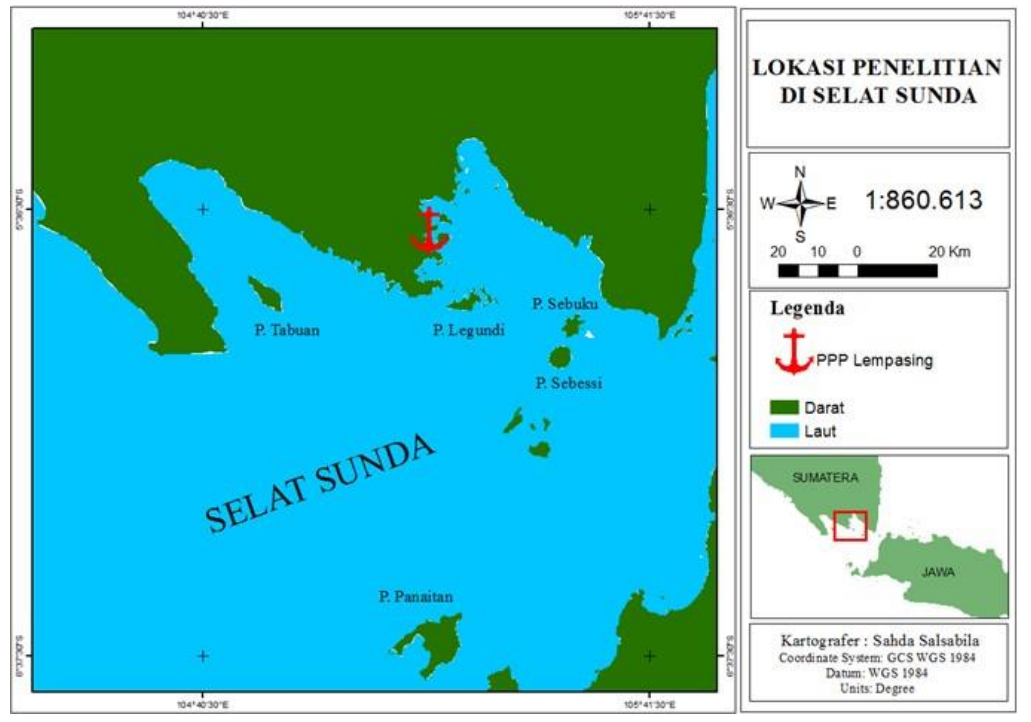

Gambar 1. Lokasi penelitian Pelabuhan Perikanan Pantai (PPP) Lempasing, Lampung 


\section{Prosedur Penelitian}

Data yang digunakan dalam penelitian ini terdiri dari data primer dan data sekunder. Pengumpulan data primer ikan dilakukan dengan mengamati ikan yang diperoleh dari para nelayan pengumpul di PPI Lempasing. Metode yang digunakan dalam penelitian ini adalah penarikan contoh acak sederhana (PCAS). Secara keseluruhan jumlah ikan contoh yang diamati sebanyak 169 ekor, 70 ekor ikan betina dan 99 ekor ikan jantan. Pengataman dilakukan untuk mendapatkan data biologi ikan, seperti panjang total, bobot basah ikan, jenis kelamin ikan, panjang usus, jenis-jenis makanan ikan kembung, jumlah tiap jenis makanan, kelompok makanan, dan volume jenis makanan ikan.

Data panjang total ikan diperoleh dari pengukuran panjang total tubuh ikan yang diukur dari mulut terdepan hingga ujung ekor terakhir menggunakan pengaris dengan ketelitian sebesar $1 \mathrm{~mm}$. Bobot ikan diperoleh dari penimbangan bobot basah total tubuh ikan yang meliputi bobot tubuh serta air yang terkandung didalamnya menggunakan timbangan digital dengan ketelitian sebesar 0,0001 gr. Jenis kelamin ikan diketahui dengan membedah ikan contoh untuk melihat gonad lalu diidentifikasi. Ikan contoh yang telah dibedah kemudian diambil lambung hingga pangkal untuk ditimbang dan diukur panjang ususnya. Isi lambung dianalisis untuk melihat jenis dan jumlah makanan. Makanan ikan diidentifikasi, dipisahkan berdasarkan jenisnya, kemudian ditimbang kembali sesuai jenisnya, serta diukur volumenya.

Data sekunder yang dibutuhkan antara lain nilai klorofil-a selama lima bulan pengamatan (Bulan Mei-September). Data tersebut diperoleh dari data penginderaan jauh sensor ocean color yang diekstrak dari citra Aqua MODIS (Moderate Resolution Imaging Spectroradiometer) level 3 monthly dengan resolusi $4 \mathrm{~km}$.

\section{Analisis Data}

\section{Indeks Bagian Terbesar (Index of Preponderance)}

Hubungan Indeks bagian terbesar makanan dihitung untuk mengetahui persentase suatu jenis makanan tertentu terhadap semua organisme makanan yang dimanfaatkan oleh ikan kembung. Indeks bagian terbesar merupakan gabungan metode frekuensi kejadian dengan volumetrik. Kebiasaan makan dapat dianalisis dengan menggunakan metode sebagai berikut.

$$
\operatorname{IP}(\%)=\frac{V i \times \text { Oi }}{\Sigma\left(V_{i} \times \mathrm{Oi}\right)} \times 100
$$

Keterangan:

$\mathrm{V}_{\mathrm{i}}$ : Persentase volume makanan ikan jenis ke-i $\mathrm{O}_{\mathrm{i}}$ : Persentase frekuensi kejadian makanan jenis ke-i

$\mathrm{N}$ : Jumlah organisme makanan luas relung makanan dihitung

\section{Pengolahan Data Aqua MODIS}

Pengolahan data Aqua MODIS dilakukan dalam beberapa tahap, yaitu pengumpulan data, pengolahan data, dan visualisasi. Pengumpulan data Aqua MODIS level 3 monthly resolusi $4 \mathrm{~km}$ selama sepuluh tahun terakhir dan selama lima bulan pengamatan yang berupa data suhu permukaan laut dan klorofil-a diekstrak menggunakan aplikasi SeaDas 7.4 window. Pengolahan data dilakukan dengan menggunakan Microsoft Excel 2007 untuk melihat nilai rataan suhu permukaan laut dan klorofil-a selama sepuluh tahun terakhir dan selama lima bulan pengamtan yang selanjutnya divisualisasikan dalam bentuk time series menggunakan grafik line untuk mengetahui variasi dari suhu permukaan laut dan konsentrasi klorofil-a. Analisa suhu permukaan laut dan konsentrasi klorofil-a yang menggunakan data suhu permukaan laut dan klorofil-a selama lima bulan pengamatan dihubungkan dengan komposisi makanan Ikan kembung lelaki (Rastrelliger kanagurta) dengan uji statistik regresi linier sederhana.

\section{Analisis Regresi Linier}

Hubungan suhu klorofil-a dengan komposisi makanan ikan kembung dianalisis menggunakan analisis regresi linier. Analisis regresi linier digunakan untuk mengukur pengaruh antara satu variabel bebas terhadap variabel terikat. Persamaan regresi linier berganda adalah sebagai berikut.

$$
\mathrm{Y}=\mathrm{aX}+\mathrm{b}
$$

\section{HASIL DAN PEMBAHASAN}

\section{Hasil}

\section{Komposisi Makanan Ikan Kembung}

Komposisi makanan mencakup jenis/ kuantitas dan kualitas makanan yang dimakan oleh ikan. Secara umum, makanan alami hasil analisis isi lambung ikan kembung lelaki di perairan Selat Sunda terbagi menjadi dua, yaitu makroorganisme dan mikroorganisme. Makanan berupa makroorganisme meliputi ikan, udang, crustacea, dan bivalvia, sedangkan makanan berupa mikrorganisme terdiri atas zooplankton dan fitoplankton. Zooplankton dan fitoplankton terbagi menjadi beberapa kelas sebagaimana disajikan pada Tabel 1.

Indeks bagian terbesar (Index of Preponderance) adalah suatu metode untuk mengetahui komposisi makanan. Komposisi makanan alami ikan kembung lelaki di perairan Selat Sunda dapat dilihat pada Gambar 2. 
Tabel 1. Makanan ikan kembung lelaki

Ketas Genus

Bacillariophyceae Asteromphalus, Bacillaria, Biddulphia, Chaetoceros, Cocconeis, Coscinodiscus, Gyrosigma, Leptocylindris, Melosira, Nitzschia, Pleurosigma, Pseudonitzschia, Rhabdonema, Rhizosolenia, Skeletonema, Staurastrum, Synedra, Thalassionema, Thalassiothrix

Dinophyceae Ceratium, Dinophysis, Gyrodinium, Navicula, Prorocentrum, Triceraitum

Cilliata Codenellopsis, Favella, Rhabdonella, Tintinnopsis

Copepoda Acartia, Catanus, Copepod, Paracalanus

Bdelloidea Synchaeta

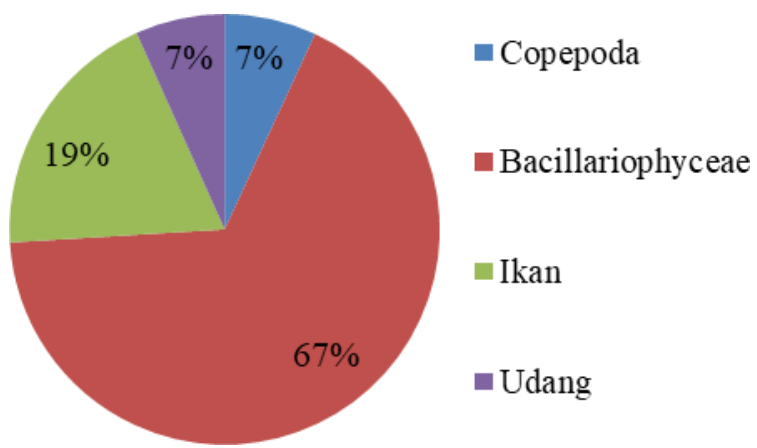

Gambar 2 Makanan ikan kembung lelaki

Komposisi makanan alami ikan kembung lelaki berdasarkan waktu pengamatan tersaji pada Gambar 3. Hubungan klorofil-a dengan komposisi makanan alami ikan kembung lelaki selama waktu pengamatan dapat dilihat pada Gambar 4.

\section{Pembahasan}

Makanan merupakan suatu zat, bahan, ataupun organisme yang dimanfaatkan oleh ikan untuk menunjang kelangsungan hidupnya. Ikan memanfaatkan energi yang berasal dari makanan untuk tumbuh, reproduksi, dan melangsungkan proses-proses fungsional organ tubuhnya. Kebiasaan makanan ikan secara alami bergantung pada lingkungan tempat hidup dan faktor-faktor yang mempengaruhi diantaranya adalah habitat, musim, umur dan ukuran ikan, periode mencari makan, kesukaan terhadap jenis tertentu dan spesies kompetitor (Febyanti dan Syahailatua 2008). Berdasarkan hasil analisis terhadap usus ikan kebung lelaki di perairan Selat Sunda yang didaratkan di PPP Lempasing, secara umum jenis organisme yang terdapat pada makanan ikan kembung lelaki terdiri atas mikroorganisme dan makroorganisme. Mikroorganisme terdiri dari zooplankton dan fitoplankton yang terbagi menjadi kelas Copepoda, Bdelloidea, Cladocera, Bacillariophyceae, Cilliata, dan Dynophyceae. Makroorganisme terdiri atas ikan, udang, bivalvia, dan crustacea. Berdasarkan komposisi jenis makanan, dapat dinyatakan bahwa ikan kembung lelaki termasuk ikan omnivora.
Berdasarkan proporsi IP, makanan alami ikan kembung lelaki di perairan Selat Sunda didominasi oleh fitoplankton kelas Bacillariophyceae. Diatom (Bacillariophyceae) merupakan kelompok fitoplankton dengan jumlah terbesar di perairan laut dan berperan penting sebagai produsen primer (Agustini et al. 2008). Tingginya keberadaan Bacillariophyceae juga diduga karena bersifat kosmopolit dan tingkat toleransinya tinggi terhadap perubahan-perubahan faktor lingkungan. Genus yang mendominasi antara lain Coscinodiscus, Asteromphalus, Nitzschia, dan Pleurosigma. Proporsi IP makanan alami ikan kembung lelaki terbesar kedua adalah ikan. Komposisi makanan alami berupa Copepoda dan udang dengan presentasi terendah. Penelitian sebelumnya yang dilakukan oleh Nath et al. (2015), makanan ikan kembung lelaki didominasi oleh Copepoda dan ikan. Hal tersebut menunjukkan adanya perbedaan bahwa komposisi makanan ikan kembung lelaki di perairan Selat Sunda didominasi oleh fitoplankton kelas Bacillariophyceae. Urutan kelimpahan organisme planktonik pada analisis isi usus tidak selalu sama. Kualitas dan kuantitas makanan ikan kembung lelaki bervariasi seiring dengan keragaman unsur planktonik dari wilayah pesisir, selain itu intensitas makan ikan kembung lelaki berbeda setiap waktu dalam setahun (Dagooghi et al. 2014).

Proporsi makanan ikan kembung lelaki di perairan Selat Sunda selama bulan pengamatan didominasi oleh fitoplankton kelas 


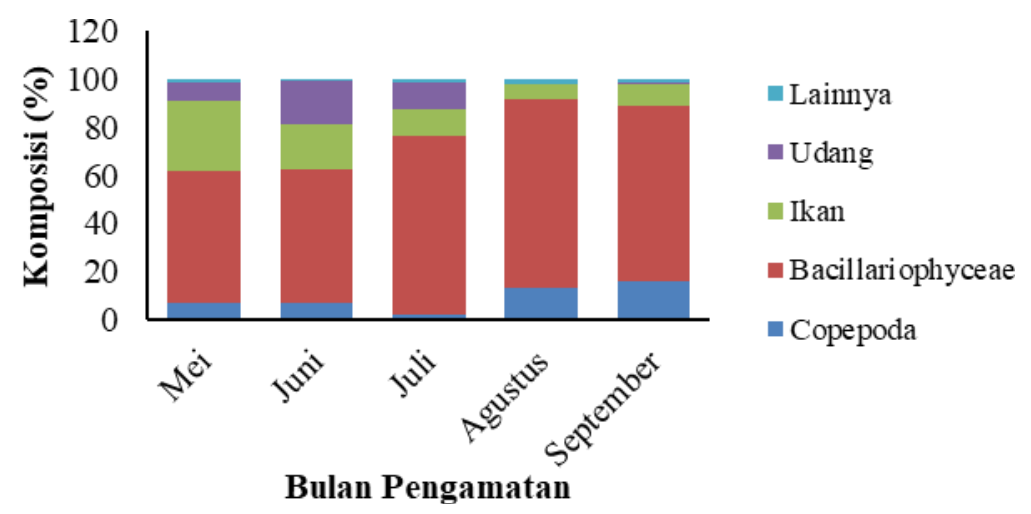

Gambar 3. Komposisi makanan alami ikan kembung lelaki berdasarkan waktu pengamatan

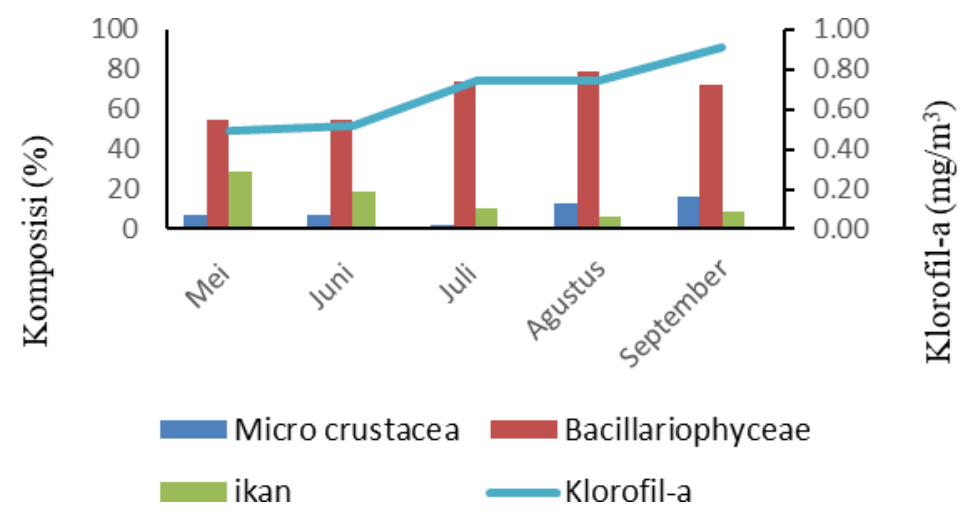

Gambar 4. Hubungan Klorofil-a dengan komposisi makanan ikan kembung lelaki

Bacillariophyceae. Hal tersebut diduga karena kelompok Bacillariophceae merupakan fitoplankton yang dominan melimpah di perairan Selat Sunda. Proporsi makanan tertinggi kedua selama bulan pengamatan adalah ikan, lalu diikuti oleh Copepoda, dan udang. Jumlah makanan alami setiap bulan pengamatan beragam. Meningkatknya konsumsi fitoplankton pada bulan Juli dan Agustus diduga karena pada bulan tersebut terjadi upwelling sehingga nutrient melimpah. Proporsi makanan ikan paling tinggi pada bulan Mei, hal ini diduga ikan kembung lelaki mencari makanan pada lapisan yang lebih dalam. Ditemukannya jenis dan kuantitas organisme yang beragam di setiap bulan pengamatan diduga dipengaruhi oleh keberadaan jenis organisme makanan di perairan Selat Sunda. Effiendi (2002) menyatakan bahwa dalam satu spesies ikan mungkin makanannya berbeda dari waktu ke waktu. Hal ini dapat dipengaruhi oleh perubahan lingkungan dan ketersediaan makanan di perairan. Sebaran klorofil-a selama waktu pengamatan di perairan Selat Sunda dapat dilihat pada Gambar 5.

Berdasarkan hasil, diketahui bahwa konsentrasi klorofil-a cenderung meningkat selama bulan pengamatan. Peningkatan nilai konsentrasi klorofil-a terlihat mulai dari bulan Juni hingga mencapai nilai tertinggi pada bulan September. Musim timur (Juni-Agustus) dan musim peralihan 2 (September-November) merupakan musim dengan tingkat kesuburan perairan yang tinggi (Amri et al. 2007). Kandungan klorofil-a di Selat Sunda dipengaruhi oleh massa air dari Laut Jawa. Arus pada musim timur dan musim peralihan relatif kuat dari arah timur (Laut Jawa) menuju Samudera Hindia. Air laut dari Jawa lebih dominan mendorong massa air hangat dengan kandungan klorofil tinggi masuk ke Selat Sunda (Aeni 2012). Kandungan klorofil-a tinggi pada musim timur dan musim peralihan 2 karena terjadinya angin muson tenggara pada bulan Juli sampai Oktober. Angin muson tenggara memicu terjadinya upwelling di Selatan Jawa karena angin muson tenggara menyebabkan massa air di Perairan Selatan Jawa mengalami sirkulasi yang sangat kuat (Ramansyah 2009). Sirkulasi yang kuat menyebabkan arus khatulistiwa selatan tertekan jauh ke utara yang menyebabkan cabang arus khatulistiwa selatan berbelok ke perairan Selat Sunda, sehingga massa air yang kaya nutrien masuk ke Perairan Selat Sunda termasuk Teluk Lampung.

Makanan ikan kembung lelaki yang sering ditemukan selama bulan pengamatan yakni fitoplankton dari kelas Bacillariophyceae, Copepoda, dan ikan. Komposisi makanan ikan kembung lelaki didominasi oleh fitoplankton dari kelas Bacillariophyceae. Bacillariophyceae 

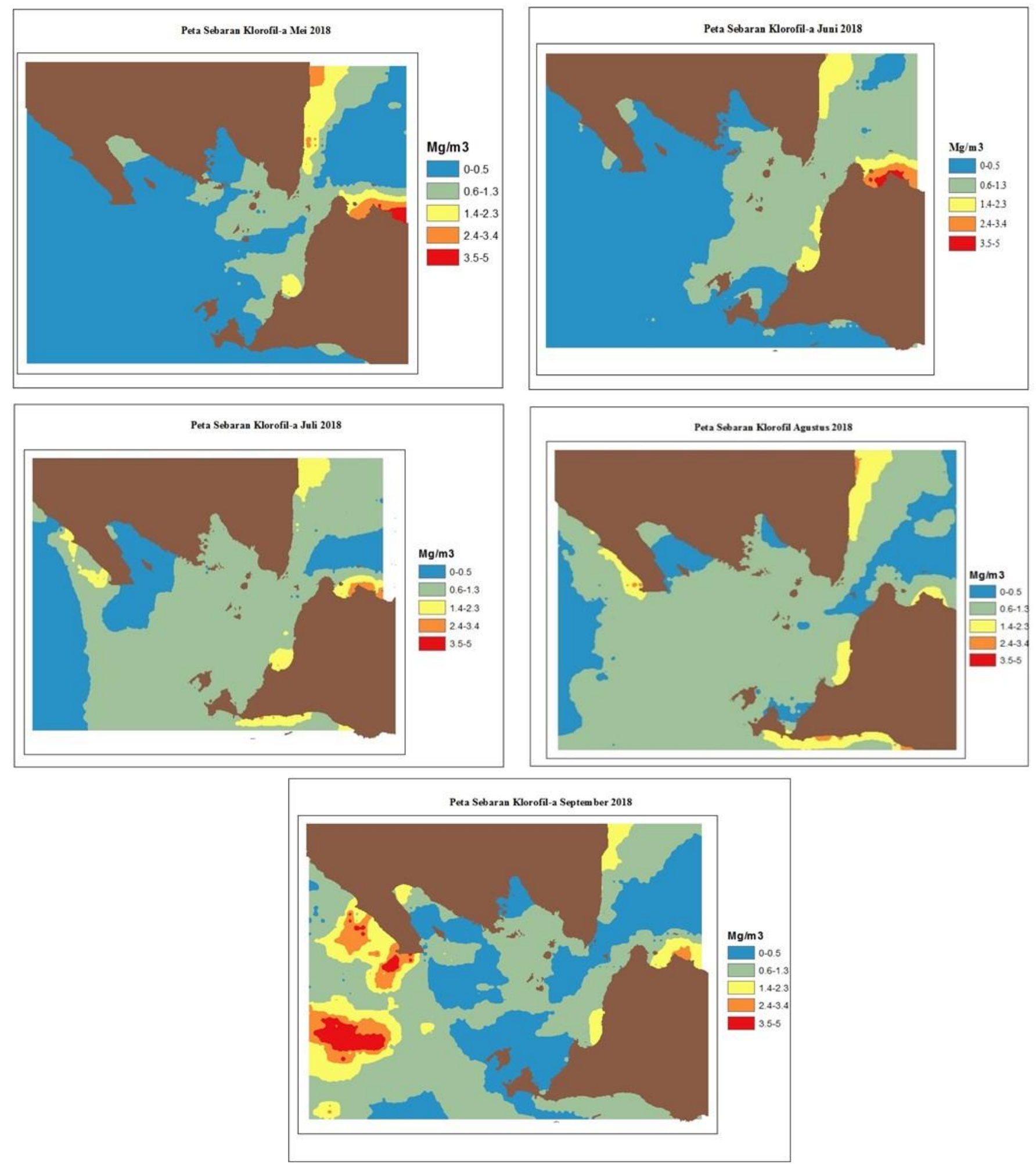

Gambar 5 Peta persebaran Klorofil-a di perairan Selat Sunda selama waktu pengamatan

merupakan kelompok fitoplankton yang paling umum yang dijumpai di laut. Hasil penelitian menunjukkan bahwa komposisi Bacillariophyceae cenderung meningkat seiring bertambahnya kandungan klorofil-a. Komposisi Bacillariophyceae tertinggi terjadi pada bulan Agustus. Hal ini diduga karena musim timur terjadi pada bulan Agustus sehingga fitoplankton melimpah di perairan. berbeda halnya dengan bulan September, komposisi makanan Bacillariophyceae mengalami penurunan dari bulan Agustus. Hal ini mungkin diperngaruhi oleh adanya waktu sela (time lag) dimana naiknya nilai klorofil-a tidak langsung berdampak pada naiknya komposisi makanan Bacillariophyceae, tetapi membutuhkan beberapa waktu sehingga klorofil yang terkandung dalam fitoplankton dimanfaatkan oleh zooplankton sebagai makanannya. Setelah itu, zooplankton akan dikonsumsi oleh ikan-ikan kecil dalam hal ini ikan kembung lelaki merupakan ikan omnivora yang dapat memanfaatkan plankton dan ikan sebagai makanannya. 
Berdasarkan uji statistik, terdapat hubungan antara parameter klorofil-a dengan komposisi makanan Bacillariophyceae. Klorofil-a terkandung dalam fitoplankton, sehingga tinggi rendahnya kelimpahan plankton dapat mempengaruhi kandungan klorofil-a di perairan (Aryawati dan Thoha 2011). Komposisi makanan mikrokrustase dan ikan mengalami fluktuasi setiap bulannya. Berdasarkan hasil terlihat bahwa peningkatan klorofil-a tidak berpengaruh langsung terhadap komposisi makanan Copeoda dan ikan. Copepoda dan ikan merupakan organisme yang berada di tingkat yang dalam kedudukannya tidak langsung memanfaatkan nutrien, sehingga keberadaannya tidak secara langsung dipengaruhi oleh banyaknya kandungan klorofil-a. Berdasarkan uji statistik, menunjukkan tidak ada pengaruh antara parameter klorofil-a dengan komposisi makanan Copepoda dan ikan. Rendahnya hubungan antara konsentrasi klorofila dengan komposisi makanan Copepoda dan ikan, diduga karena selama fitoplankton masih tersedia di perairan maka Copepoda dan ikan akan tetap ada.

\section{KESIMPULAN}

Klorofil-a terkandung dalam fitoplankton sehingga mempengaruhi kelimpahan fitoplankton. Peningkatan klorofil-a diikuti dengan meningkatknya komposisi makanan fitoplankton yakni Bacillariophyceae. Komposisi makanan alami ikan tertinggi terdapat pada bulan Mei, dimana kandungan klorofil-a lebih rendah daripada waktu pengamatan lainnya. Komposisi makanan Bacillariophyceae tertinggi terdapat pada bulan Agustus, dengan kandungan klorofil-a yang tinggi. Melimpahnya plankton pada bulan Agustus diduga karena adanya upwelling.

\section{DAFTAR PUSTAKA}

Aeni N. 2012. Analisis suhu permukaan laut dan klorofil-a dari citra aqua modis serta hubungannya dengan hasil tangkapan ikan pelagis di Selat Sunda [skripsi]. Bogor (ID): Insitut Pertanian Bogor.

Agustini T, Wardhana W, \& Patria MP. 2008. Kebiasaan Makanan Balanus amphitritte dan Hubungannya dengan Kelimpahan Plankton di Suralaya, Banten [laporan penelitian]. Departemen Biologi FMIPA-UI, Depok. 110.

Amri K, Manurung D, Siregar VP. 2007. Dinamika kondisi oseanografi musiman Perairan Selat Sunda dari analisis data multitemporal. Jurnal Penelitian Perikanan Indonesia. 13(3): 191-199.

Aryawati R, Thoha H. 2011. Hubungan kandungan klorofil-a dan kelimpahan fitoplankton di Perairan Berau Kalimantan Timur. Maspari Journal. 2: 89-94.

Bhendarkar MP, Naik SD, Sonone AD, Wankhade HP, Joshi HD. 2014. Feeding biology of the of Indian mackerel, Rastrelliger kanagurta (Cuvier, 1817) off Ratnagiri coast, Maharashtra, India. 20(3): 1147-1152.

Daghooghi B, Kaymaram F, Vosoughi A, Valinassab T, Moradi M. 2014. Evaluation of some feeding habits of Rastrelliger kanagurta (Cuvier, 1817) in the Persian Gulf (Hormozgan Province). Indian Journal of Fisheries Sciences

Effendie MI. 2002. Biologi Perikanan. Yogyakarta (ID): Yayasan Pustaka Nusatama. Febyanty F, Syahailatua A. 2008. Kebiasaan Makanan Ikan Terbang, Hirundicthys oxycephalus dan Cheilopogon cyanopterus, di Perairan Selat Makasar [laporan penelitian]. Fakultas Perikanan dan Ilmu Kelautan \& Pusat Penelitian OseanografiLembaga Ilmu Pengetahuan Indonesia. 1-8.

Kasim K, Triwahyuni S, Wujdi A. 2014. Hubungan ikan pelagis dengan konsentrasi klorofil-a di Laut Jawa. Bawal. 6(1): 21-29.

Nath SR, Beraki T, Abraha A, Abraham K, Berhane Y. 2015. Gut content analysis of indian mackerel (Rastrelliger kanagurta). Journal of Aquaculture \& Marine Biology. 3 (1): 1-5.

Ramansyah F. 2009. Penentuan Pola Sebaran Konsentrasi Klorofil-a di Selat Sunda dan Perairan Sekitarnya dengan Menggunakan Data Inderaan Aqua Modis [skripsi]. Bogor (ID) : Institut Pertanian Bogor.

Sihombing IN, Hutabarat A, Sulardiono B. 2015. Kajian kesuburan perairan berdasarkan unsur hara $(\mathrm{N}, \mathrm{P})$ dan fitoplankton di sungai Tulung Demak. Diponegoro Journal of Maquares. 4 (4): 119-127.

Utami MN, Sri R, Endang S. Komposisi isi lambung Ikan kembung lelaki (Rastrelliger kanagurta) di Rembang. Journal of Marine Research. Semarang. 2(3): 99-106. 